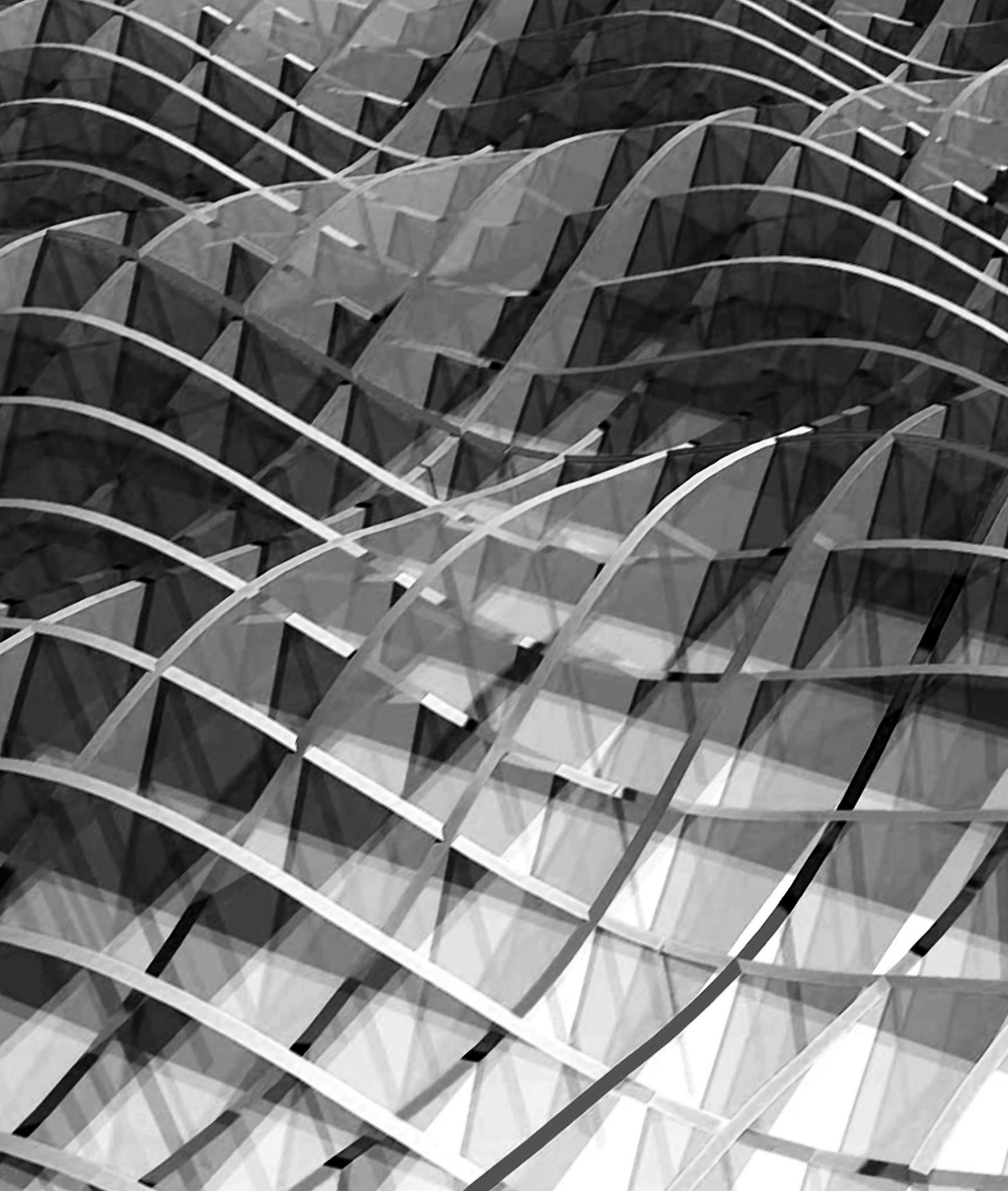


FELIPE CORVALÁN TAPIA

Editor Revista de Arquitectura Facultad de Arquitectura y Urbanismo Universidad de Chile

\section{Teoría del Proyecto}

\begin{abstract}
- n las páginas iniciales de El ARTESANO, Richard Sennett señala que "hacer es pensar", cuestionando el exceso de — producción sin sentido que domina a la cultura contemporánea. Utilizando como referencia el trabajo artesanal, Sennett plantea la necesidad de recuperar el hacer como una acto reflexivo, es decir, como una instancia en la que permanentemente interactúan teoría y práctica. Una mirada que cobra sentido en el ámbito de la arquitectura, cuyos límites disciplinares configuran un territorio fronterizo entre concepto y ejecución, entre idea y materialización.
\end{abstract}

Intentando estimular el debate en torno a los idearios que sustentan las prácticas arquitectónicas, la edición número 30 de ReVISTA DE ARquITECTURA aborda como tema central aquello que se denomina Teoría del Proyecto. Una instancia recurrentemente citada al interior de la disciplina, pero no del todo esclarecida, que nos permite aproximarnos a los fundamentos y metodologías del ejercicio proyectual, así como también a sus tensiones y discontinuidades.

El artículo de Fabián Barros abre la discusión planteando las preguntas esenciales: ¿̇qué es la teoría del proyecto?; ¿̇cuáles son sus alcances?; ¿̇cuál es la relación o diferencia entre esta instancia arquitectónica y las indagaciones reflexivas originadas en otras disciplinas? Interrogantes que son abordadas a partir del estudio y análisis de autoresarquitectos que durante el siglo XX fueron fundamentales para la construcción de un espacio de reflexión crítico en torno al proyecto y sus operaciones.

Continuando la discusión, el texto de Claudio Palavecino constituye una interesante reflexión en torno a las implicancias del proceso de diseño, sus límites, restricciones y oportunidades. Analizando su propia experiencia proyectual, el autor entiende al diseño arquitectónico como una instancia exploratoria, en cuya trayectoria conviven y se superponen planificación y arbitrariedad.

En el caso de Daniel Martínez, su trabajo centra la atención en la obra del arquitecto francés Jean Prouvé, cuya labor permite poner en evidencia el recíproco vínculo entre técnica y proyecto. En función del trabajo de Prouvé, es posible pensar al proyecto como un proceso generativo y también experimental, asociado al desarrollo tecnológico.

Por su parte, el artículo de Francisco Muñoz plantea un diálogo entre el trabajo de Mies van der Rohe y la oficina japonesa SANAA (Sejima + Nishizawa). Pese a la distancia temporal, el autor reconoce en este diálogo una suerte de influencia proyectual, reavivando el debate en torno a la autorreferencialidad del campo arquitectónico. Un debate que se complementa con el artículo de Arturo Tomillo y su lectura sobre el Museo Nacional de Arte Romano de Mérida de Rafael Moneo, un proyecto que para Tomillo combina el análisis tipológico con un particular interés en la valoración del tiempo como fundamento proyectual.

Ampliando la escala de observación, el artículo de Alfonso González indaga en el diseño urbano y su impacto sobre la configuración del espacio público y sus habitantes. Tomando como referencia el caso de la ciudad de Barcelona, el autor plantea una mirada crítica sobre el ejercicio proyectual centrado en consideraciones meramente estéticas o formales, argumentando que tal aproximación desatiende y simplifica el conjunto de variables y disputas socioculturales que configuran el ámbito de lo urbano.

Cierra este cuerpo de artículos, el texto de $M^{a}$ Luisa López Sardá. Un trabajo que da cuenta de los principales hallazgos del libro ACORDES ARQUITECTÓNICOS: OTRA GEOMETRÍA DE LA PROPORCIÓN Y LA ARMONÍA EN LA ARQUITECTURA, resituando conceptos clásicos como el de armonía o proporción en función de las nuevas teorías físicas y su vinculación con el carácter proyectual propio de la arquitectura.

Para finalizar, incorporamos una muestra reciente del trabajo de los estudiantes de pregrado de nuestra Facultad. Se trata del seminario de investigación de quinto año de la alumna Katia Munjin, "Antifragilidad en la Arquitectura. Sistema orgánico para resistir el desorden y evolucionar" y del proyecto de título de Sebastián Loaiza, "Intermodal social Yonghgeong". Dos miradas que nos recuerdan, una vez más, la recurrente interacción entre concepción y operación que en esta edición de ReVISTA DE ARQUITECTURA hemos intentado pensar a través de la noción de Teoría del Proyecto. 